\title{
Determination of Minimum Inhibitory Concentration (MIC), Mutation Frequency and Plasmid Extraction and Transformation of Antibiotic resistant bacterial isolate from Aquatic Environment
}

\author{
Hemanta Pokhrel*, Salini Gopi, Devika Pillai, C.G. Rakesh and K.G. Sneha
}

Centre for Aquatic Animal Health Management, School of Aquaculture and Biotechnology Kerala University of Fisheries and Ocean Studies, India

*Corresponding author

\section{A B S T R A C T}

\begin{tabular}{|l|}
\hline Ke y w o r d s \\
Antimicrobial \\
resistance, \\
Minimum inhibitory \\
concentration \\
(MIC), Mutation, \\
Plasmid \\
transfermation, \\
Conjugation
\end{tabular}

\section{Introduction}

Antimicrobial resistance (AMR), which is one of the most serious global public health concerns in today's world, has almost reached crisis stage in human medicine. The rapid acceleration of multidrug-resistant bacteria in the past decades has overtaken new drug development and patients and clinicians are
The present study is done to determine the lowest concentration of the assayed antimicrobial agent (minimal inhibitory concentration, MIC) that, under defined test conditions, inhibits the visible growth of the bacterium. MIC values are also used to determine susceptibilities of bacteria to drugs and also to evaluate the activity of new antimicrobial agents, mutation frequency the several factors that affect the appearance and spread of acquired antibiotic resistance and plasmid extraction and transformation demonstrates that conjugation and transfer of plasmids, a phenomenon that belongs to the environment and can occur between bacterial strains of human, animal, and fish origins that are unrelated either evolutionarily or ecologically even in the absence of antibiotics. MIC concentration in the study was found to be in the higher side. For maximum number of strains MIC for ampicillin ranged from 2 to $64 \mu \mathrm{g}$ with maximum at $64 \mu \mathrm{g}$ shown by Kluyvera intermedia and minimum $2 \mu \mathrm{g}$ shown by various strains like Acinetobacter johnsonii, Edwarsiella spp and Pseudomonas alcaligenes. Mutation frequency was also done in order to determine the rate at which the isolates mutate to acquire resistance for a particular antibiotic. The results indicate that bacteria can mutate and develop resistance to an antibiotic on prolonged exposure. Plasmid extraction and transformation process was also performed in order to understand the process of resistance transformation. One of the major mechanisms of transfer of AMR was found to be plasmid mediated. 
environmental exposures in a variety of water bodies, which select for resistant microbes and microbial genes. Although various authors also have emphasized the putative negative effects of using antimicrobial agents in fish farms (Cabello, 2006), few studies on antimicrobial resistance in the aquaculture industry have been performed in situ (Johnson et al., 2010). However, disease control is an active research field, and alternatives to antibiotic treatments are being explored. The public health hazards related to antimicrobial use in aquaculture include the development and spread of antimicrobial-resistant bacteria and resistance genes and the presence of antimicrobial residues in aquaculture products and the environment.

Antimicrobials are now ubiquitous in the environment They are used in human medicine by prescription, in over-the-counter preparations, by veterinarians to treat disease in animals, in cleaning products and other consumer products, as pesticides, in aquaculture (fish farming), and in animal agriculture (Levy, 1998). The largest use of antimicrobial agents outside human medicine is in food animals (Swartz, 1989). During the past 30 years, studies have shown that use of antimicrobials in food animal production promotes the development and subsequent dissemination to humans of resistant organisms (NRCCD, 1999). Resistance genes are bred and transferred within environmental reservoirs in which bacteria and antimicrobial agents coexist. Obvious reservoirs include the guts of humans and animals, in which horizontal resistance gene transfer has been documented among pathogenic and commensal species (Shoemaker et al., 1992 and Kuramitsu (2001). Active antibiotics have been identified in water near wastewater treatment plants, animal waste lagoons surface waters, and river sediments (Myer, 2000). This has resulted in speculation that environmental contamination with antibiotics can augment the selection and dissemination of resistance genes through a wide variety of routes involving animal and nonanimal reservoirs.

Thus this study presents the major lines of evidence documenting the risks to human health of some of the use and misuse of antimicrobials in hospital, aquaculture and in agricultural.

\section{Materials and Methods}

\section{Isolation and identification of bacteria}

The bacterial colonies that grew on the media were selected, purified and subjected to morphological and biochemical tests for identification. Tests carried out for identification included Gram's stain, catalase, oxidase, coagulase, motility, O-F, indole, gelatin hydrolysis, methyl-red, VogesProskauer, ONPG, lysine decarboxylase, citrate utilization, Triple Sugar Iron (TSI) agar, nitrate reduction and fermentation of sugars such as Fructose (Fc 25mg), Melibiose (Me 25mg), Sucrose (Su 25mg), Cellobiose (Ce $25 \mathrm{mg}$ ), Xylose (Xy 25mg), Galactose (Ga 25mg), Mannose (Mo 25mg), Trehalose (Te 25mg), Inositol (Is 25mg), Dulcitol (Du 25mg), Dextrose (De 25mg), Mannitol (Mn 25mg), Lactose (La 25mg), Adonitol (Ad 25 $\mathrm{mg}$ ), Sorbitol ( $\mathrm{Sb} 25 \mathrm{mg}$ ), Rhamnose (Rh 25mg), Maltose (Ma 25mg), Raffinose (Rf 25mg), Arabinose (Ar 25mg), Salicin (Sa 25mg), Inulin (In 25mg).

\section{Minimum Inhibitory Concentration determination (MIC)}

The minimum inhibitory concentration (MICs) of the different antibiotics was also determined by the standard agar diffusion test (Bauer et al., 1996) on Muller-Hinton agar for different bacterial isolates. 18 different $\mathrm{Hi}$ comb Minimum inhibitory concentration strips 
(MICs strips Hi media) which were used in the study were Ampicillin (AMP 240-0.01 $\mu \mathrm{g}$ ),

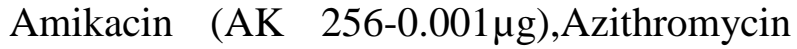
(AZM 128-0.0001 $\mu \mathrm{g}$ ), Carbenicillin (CB 512-

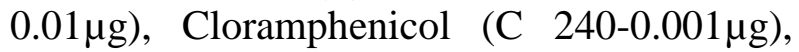
Co-trimoxazole (COT 240-0.001 $\mu \mathrm{g}$ ), Ciprofloxacin (CIP 240-0.001 $\mu$ g), Cefepime (CPM 240-0.001 $\mu \mathrm{g}$ ),Erythromycin (E 240$0.001 \mu \mathrm{g})$ Gentamicin (GEN 240$0.001 \mu \mathrm{g})$, Kanamycin $\quad(\mathrm{K} \quad 240-0.001 \mu \mathrm{g})$, Methicillin (MET 240-0.001 $\mu \mathrm{g}$ ),Nalidixic acid (NA 240-0.001 $\mu \mathrm{g}$ ), Nitrofurantion (NIT 240-

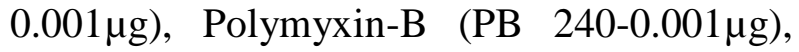
Streptomycin (S 240-0.001 $\mu \mathrm{g}$ ), Tetracycline (TE 240-0.001 $\mu \mathrm{g}$ )and Vancomycin (VA 256$0.001 \mu \mathrm{g})$.

The plates were prepared and bacterial culture was spread on the plates as described in the previous section on antibiotic susceptibility test. Hi comb MIC strips (Hi media, Mumbai) were placed on the agar media with the MIC scale facing upward with the help of a sterile forceps. The plates were then incubated at room temperature for 12 to $15 \mathrm{~h}$ and were observed. Zones of growth inhibition were evaluated according to the Clinical and Laboratory Standards Institute (CLSI) standard (CLSI, 2009).

\section{Mutation frequency}

Two vancomycin sensitive strain, viz., Klebsiella oxytoca and Enterobacter aerogenes isolated from water and sediments samples from the sampling stations were used for determining the mutants resistant to vancomycin. Mutation frequency was estimated by the method of Barnes et al. (1991).

Two conical flasks, each containing $100 \mathrm{ml}$ of drug free Tryptone soya broth (TSB) were inoculated with vancomycin sensitive strains Klebsiella oxytoca and Enterobacter aerogenes. The inoculated broth was shaken overnight at room temperature. The resulting cultures were then centrifuged at $10000 \mathrm{~g}$ for 8 min. The supernatant was decanted and the pellet was resuspended in $2 \mathrm{ml}$ of freshly prepared TSB to obtain a cell concentration of about $10^{10} \mathrm{cfu} \mathrm{ml}^{-1}$. The culture was then diluted for four- folds i.e. $10^{-1}, 10^{-2}, 10^{-3}, 10^{-4}$ in pre-autoclaved aliquots. The diluted cultures were then spread properly and aseptically on TSA plates containing antibiotics at 5, 10, 15, 20 times the MIC. The inoculated plates were incubated at $22^{\circ} \mathrm{C}$ and examined daily for 7 days for the presence of any resistant colonies. Resistant colonies which appeared on the plate were again subcultured onto fresh TSA plate containing an antibiotic. The number of colonies on the plates was counted and mutation frequency was calculated (Lee et al., 2014).

\section{Plasmid extraction}

Plasmids were isolated from all the isolates by the method of (Elkin et al., 2001) with modification. $5 \mathrm{ml}$ of LB broth was inoculated with a single colony and grown overnight at $37^{0} \mathrm{C}$. Pellet was obtained by centrifuging the colony at $8000 \mathrm{rpm}$ at $4^{0} \mathrm{C}$. Pellet was suspended in $150 \mu \mathrm{l}$ of GTE buffer $(50 \mathrm{mM}$ glucose, $25 \mathrm{mM}$ Tris $\mathrm{HCl}, 10 \mathrm{mM}$ EDTA $(\mathrm{pH}$ 8.0)], vortexed well and kept at room temperature for $5 \mathrm{~min}$. Then $150 \mu \mathrm{l}$ of lysis solution $(0.2 \mathrm{M} \mathrm{NaOH}$ and $1 \% \mathrm{SDS})$ was added and kept at room temperature for $5 \mathrm{~min}$ for lysis of cells. To the lysate, $150 \mu \mathrm{l}$ of neutralization buffer (5M potassium acetate; $\mathrm{pH} 4.5$ ) was added and kept on ice for $10 \mathrm{~min}$, followed by centrifugation at 8000rpm for 10 min. The supernatant was transferred to a fresh tube and precipitated with 0.7 volume of isopropanol and kept at RT for $10 \mathrm{~min}$. The tubes were centrifuged at $14000 \mathrm{rpm}$ for 20 min to pellet the plasmids. Pellet was dried and resuspended in $50 \mu \mathrm{l}$ TE buffer. $5 \mu \mathrm{l}$ of plasmid DNA was then mixed with $1 \mu \mathrm{l}$ of $6 \mathrm{X}$ loading dye and subjected to electrophoresis in 
$1 \%$ agarose gel. The bands were visualized in a gel documentation system (Biorad, USA). The molecular weight of plasmids was determined by comparing with Escherichia coli V517 plasmids.

\section{Preparation of $E$ coli HB101 competent cells}

Single colony of $E$ coli HB101 was inoculated into $10 \mathrm{ml}$ of LB broth and grown overnight at $37^{\circ} \mathrm{C}$ with constant shaking at $150 \mathrm{rpm}$. The following day, $1 \mathrm{ml}$ of overnight culture was transferred into $100 \mathrm{ml}$ of LB broth and incubated for 90-120 min with vigorous shaking at $200 \mathrm{rpm}$ at $37^{\circ} \mathrm{C}$. Optical density at $600 \mathrm{~nm}\left(\mathrm{OD}_{600}\right)$ was measured after every 30 min. When $\mathrm{OD}_{600}$ reached 0.4-0.5, culture was chilled on ice, transferred to pre-chilled $2 \mathrm{ml}$ polypropylene tubes and centrifuged at $4000 \times$ $g$ for 10 min using cooling centrifuge (Remi). The supernatant was discarded and the cell pellet was suspended gently without damaging the cells in $1 \mathrm{ml}$ of ice cold $0.1 \mathrm{M} \mathrm{CaCl}_{2}$ and the suspension was kept on ice for an additional $90 \mathrm{~min}$ and centrifuged at $2500 \mathrm{rpm}$ at $4{ }^{\circ} \mathrm{C}$ for $10 \mathrm{~min}$. The supernatant was discarded carefully and the cell pellet was resuspended in $1 \mathrm{ml}$ of ice cold $0.1 \mathrm{M} \mathrm{CaCl}$. About $150 \mu \mathrm{l}$ suspension of competent cells was aliquoted in $1.5 \mathrm{ml}$ microfuge tubes, frozen and stored at $-80^{\circ} \mathrm{C}$.

\section{Transformation}

$2 \mu \mathrm{l}$ of the plasmid DNA was added into the thawed tube containing $200 \mu \mathrm{l} E$ coli HB101competent cells. This was then mixed gently by tapping the tube and the transformation mixture thus obtained was incubated on ice for $20 \mathrm{~min}$. During this incubation period, LB medium was prewarmed to $42^{\circ} \mathrm{C}$. Heat-shock was given to the transformation mixture by placing the tube in water bath set at $42^{\circ} \mathrm{C}$ for $45 \mathrm{sec}$ followed immediately by incubating on ice for $2 \mathrm{~min}$.
To this transformation reaction mixture, 250 $\mu l$ of pre-warmed Luria Bertani medium was added. The competent cells were allowed to recover for 1.30 hours at $37^{\circ} \mathrm{C}$ with agitation on a horizontal shaker. $100 \mu \mathrm{l}$ of the transformation mixture was then plated on LB-agar plates containing Vancomycin $(30 \mu \mathrm{g} / \mathrm{ml})$ and incubated at $37^{\circ} \mathrm{C}$ for overnight.

\section{Results and Discussion}

In the present study a total of 56 bacteria were isolated, of which 32 from fish 12 from shrimp and 12 from clam Among the 105 isolates recovered from the samples collected, $(90.47 \%)$ tested positive for Methicillin resistance by disc diffusion.

\section{Minimum Inhibitory Concentration (MIC)}

For maximum number of bacterial isolates MIC for ampicillin ranged from 2 to $64 \mu \mathrm{g}$ with maximum at $64 \mu \mathrm{g}$ shown by Kluyvera intermedia and minimum $2 \mu \mathrm{g}$ shown by various strain like Acinetobacter johnsonii, Edwarsiella spp and Pseudomonas alcaligenes. The minimum value of MIC obtained for ampicillin was $0.016 \mu \mathrm{g}$ for Bacillus circulans.

For methicillin, out of 16 isolates 10 were completely resistant. The strains which were resistant to methicillin were Klebsiella pneumoniae, Klebsiella oxytoca, Acinetobacter johnsonii, Streptococcus spp, Edwarsiella spp, Pseudomonas alcaligenes etc. For other strains MIC for methicillin ranged from 5 to $30 \mu \mathrm{g}$ with maximum value $30 \mu \mathrm{g}$ shown by Flavobacterium breve and minimum $5 \mu \mathrm{g}$ shown by various isolates like Bacillus circulans, Enterobacter aerogenes and Penaeibacillus lautus. The minimum value of MIC for methicillin was $0.1 \mu \mathrm{g}$ for Enterococcus phoeniculicola. For maximum number of strains MIC for Vancomycin 
ranged from 2 to $128 \mu \mathrm{g}$ with maximum ranged $128 \mu \mathrm{g}$ for Streptococcus equi and minimum $2 \mu \mathrm{g}$ for Enterococcus phoeniculicola. The minimum MIC value for vancomycin was $0.064 \mu \mathrm{g}$ by Enterobacter aerogenes (Fig.1).

Similarly for other strains, the maximum MIC value reported for ciprofloxacin and streptomycin was $240 \mu \mathrm{g}$, while for carbenicillin the value was $128 \mu \mathrm{g}$ and for polymyxin B and erythromycin the MIC value was $120 \mu \mathrm{g}$. The MIC results for various antibiotic used against different bacterial isolate are shown in the Table 1.

\section{Mutation frequency}

The mutation frequencies at which two vancomycin susceptible strains of Klebsiella oxytoca and Enterobacter aerogenes mutated to develop resistance when exposed to vancomycin, were determined at drug concentration of 5, 10, 15 and 20 times of their respective MIC's $0.256 \mu \mathrm{g}$ and $0.064 \mu \mathrm{g}$. Mutants' resistance to vancomycin isolated at 5, 10 and 15 times the MICs frequencies, is given in Table 2. However, at 20 times the MIC, the mutation frequency of Klebsiella oxytoca was not detectable (ND), which was the limit of detection of this experiment. Since the MIC concentration of Enterobacter aerogenes was less $(0.064 \mu \mathrm{g})$ the mutation frequencies obtained was less compared to $K$. oxytoca and mutation was not recorded at 15 and 20 times of MIC for the isolate (Table 3.).

\section{Plasmid extraction and transformation}

Transformation was done with isolated strains containing the resistance gene encoded plasmid as the donor cells and the E.coliHB101 strains as the recipients (Chen and Dubnau, 2004). A total of 105 strains were segregated during the study period and among these, 15 were used for the plasmid extraction. Out of 15 selected multidrug resistant isolates, 10 strains showed detectable plasmids, and these 10 strains were used for the plasmid transformation study. The names of the strains and their plasmid profile are given in Table 4 and in figure 2 respectively. The plasmid from Escherchia coli V.157 was used as marker to determine the size of the plasmid (Macrina et al., 1982.)

Plasmid analysis revealed that there were detectable plasmids in 10 isolates out of 15 selected multidrug resistant isolates. Five of the isolates possessed no plasmid, two of the isolates viz., Bacillus circulans and Streptococcus spp possessed single plasmids of size 4.4 (lane 4) and $6.6 \mathrm{~kb}$ (lane 5), respectively.

Acinetobacter johnsoniii was found to harbour 6 plasmids of size ranging from 2 to $23 \mathrm{~kb}$ (lane 6). Enterobacter aerogenes (lane3) and Enterococcus phoeniculicola (lane 7) was found to carry four numbers of plasmid each. Four of the isolates Klebsiella pneumonia (lane1), Klebsiella oxytoca (lane 2), Enterobacter aerogenes, Enterococcus phoeniculicola harboured a similar sized common plasmid of size $4.4 \mathrm{~kb}$.

After the transformation process the isolates were exposed to varying concentrations of 18 different antibiotics. The transformed strains showed resistance to different antibiotics to which they were initially susceptible. The list of antibiotics to which it gained resistance after transformation is given below in Table 5 .

Among all the different isolates from the study area, the most commonly and frequently encountered strain was Klebsiella pneumonia and Klebsiella oxytoca. Among them, Klebsiella pneumoniae was the predominant strain in all samples. Being clinical isolates, their presence in significant numbers distinctly point to their source as the hospital effluents. 
Table.1 Showing MIC results for various antibiotics used against different bacterial isolate

\begin{tabular}{|c|c|c|c|c|c|c|c|c|c|c|c|c|c|}
\hline \multirow[b]{2}{*}{ Test } & \multicolumn{13}{|c|}{ Hi comb MIC strips } \\
\hline & \multicolumn{13}{|c|}{ Isolated strains } \\
\hline 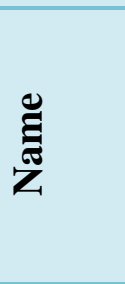 & 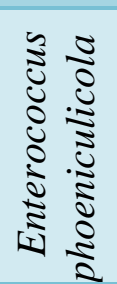 & 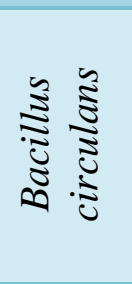 & 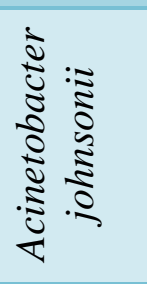 & 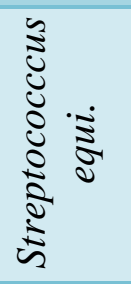 & 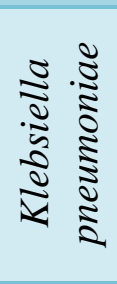 & 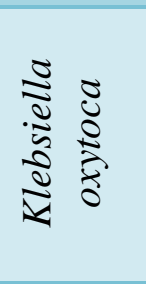 & 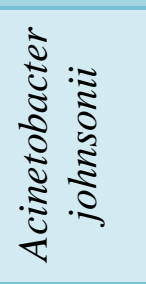 & 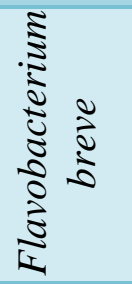 & 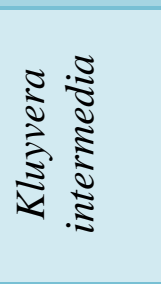 & 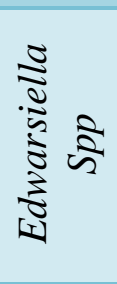 & 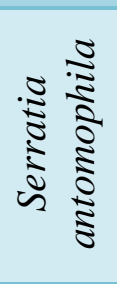 & 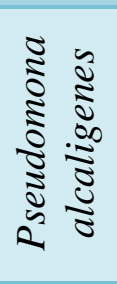 & $\begin{array}{cc}0 & \\
0 & y \\
0 & 0 \\
0 & 0 \\
0 & 0 \\
0 & 0 \\
0 & 0 \\
\vdots & 0 \\
0 & 0\end{array}$ \\
\hline AMP & 0.016 & 0.016 & 2 & 8 & - & - & 2 & 4 & 64 & 2 & 4 & 2 & 4 \\
\hline AK & 0.01 & 0.01 & 0.1 & 0.1 & 256 & 4 & 0.1 & 0.01 & 0.1 & 0.1 & - & 0.1 & - \\
\hline $\mathbf{A Z M}$ & 0.10 & 0.01 & 0.1 & 0.01 & - & - & .1 & 0.01 & 0.01 & 0.1 & 0.5 & 0.1 & 0.5 \\
\hline CB & 1 & 4 & - & - & - & 16 & - & - & 32 & 128 & 4 & - & 4 \\
\hline $\mathbf{C}$ & 0.01 & 0.1 & 0.1 & 0.1 & - & 10 & 0.1 & 10 & 0.01 & 0 & 1 & 0.1 & 1 \\
\hline CIP & 0.01 & 0.01 & 0.1 & 0.01 & 240 & 10 & 0.1 & 0.01 & 0.004 & 0.01 & 0.1 & 0.1 & 0.1 \\
\hline COT & 10 & 0.01 & 10 & 5 & - & - & 10 & .1 & 5 & 0.1 & - & - & - \\
\hline CPM & 0.1 & - & 0.1 & 1 & - & 7.5 & 0.1 & 1 & - & 30 & 5 & 0.1 & 5 \\
\hline $\mathbf{E}$ & 0.01 & 0.1 & 120 & 5 & - & - & 120 & 5 & 5 & - & 0.1 & 120 & 0.1 \\
\hline GEN & 0.01 & 0.01 & 0.1 & 0.1 & - & 2 & 0.1 & 1 & 10 & 5 & - & 0.1 & - \\
\hline K & 0.1 & 0.1 & 1 & 5 & - & 60 & 1 & 1 & 1 & 10 & 5 & 1 & 10 \\
\hline MET & 0.1 & 5 & - & - & - & - & - & 30 & - & - & 5 & - & 5 \\
\hline NA & 0.1 & 0.1 & 0.1 & 0.1 & - & - & 0.1 & 0.1 & 0.1 & 5 & 0.1 & 0.1 & 5 \\
\hline NIT & 0.1 & 10 & 10 & 5 & - & - & 10 & - & 10 & - & 5 & 10 & 5 \\
\hline PB & 5 & 5 & 5 & 5 & 120 & 5 & 5 & 0.1 & 10 & - & 5 & 5 & 5 \\
\hline $\mathbf{S}$ & 0.1 & 0.1 & 1 & 0.1 & 240 & 3 & 1 & 0.1 & 0.1 & 10 & 1 & 1 & 1 \\
\hline TE & 0.01 & 0.01 & 0.1 & 0.01 & - & 0.25 & 0.1 & 0.01 & 0.01 & 0.1 & 0.1 & 0.1 & 0.01 \\
\hline VA & 2 & 4 & 64 & 128 & - & 0.246 & 64 & 32 & - & - & - & 64 & 0.064 \\
\hline
\end{tabular}


Table.2 Range of mutation frequencies for vancomycin sensitive strain of Klebsiella oxytoca

\begin{tabular}{|c|l|l|l|l|}
\hline \multirow{2}{*}{ Drug } & \multicolumn{4}{|c|}{ Mutation frequencies at } \\
\cline { 2 - 5 } & $5 \times \mathrm{MIC}$ & $10 \times \mathrm{MIC}$ & $15 \times \mathrm{MIC}$ & $20 \times \mathrm{MIC}$ \\
\hline Vancomycin $\left(\mathbf{R}_{\mathbf{1}}\right)$ & $3.5-3.84 \times 10^{-3}$ & $2.15-2.33 \times 10^{-3}$ & $0.24-1.1 \times 10^{-3}$ & $\mathrm{ND}$ \\
\hline$\left(\mathbf{R}_{\mathbf{2}}\right)$ & $3.2-3.6 \times 10^{-3}$ & $2.0-2.1 \times 10^{-3}$ & $0.16-0.9 \times 10^{-3}$ & $\mathrm{ND}$ \\
\hline
\end{tabular}

Table.3 Range of mutation frequencies for vancomycin sensitive strain of Enterobacter aerogenes

\begin{tabular}{|c|c|c|c|c|}
\hline \multirow[t]{2}{*}{ Drug } & \multicolumn{4}{|c|}{ Mutation frequencies at } \\
\hline & $5 \times \mathrm{MIC}$ & $10 \times \mathrm{MIC}$ & $15 \times \mathrm{MIC}$ & $20 \times \mathrm{MIC}$ \\
\hline Vancomycin $\left(R_{1}\right)$ & $1.53-1.86 \times 10^{-3}$ & $0.15-0.55 \times 10^{-3}$ & ND & ND \\
\hline$\left(\mathbf{R}_{2}\right)$ & $1.23-1.43 \times 10^{-3}$ & $0.11-0.21 \times 10^{-3}$ & ND & ND \\
\hline
\end{tabular}

Fig.1 Showing methicillin resistant Klebsiella pneumoniae

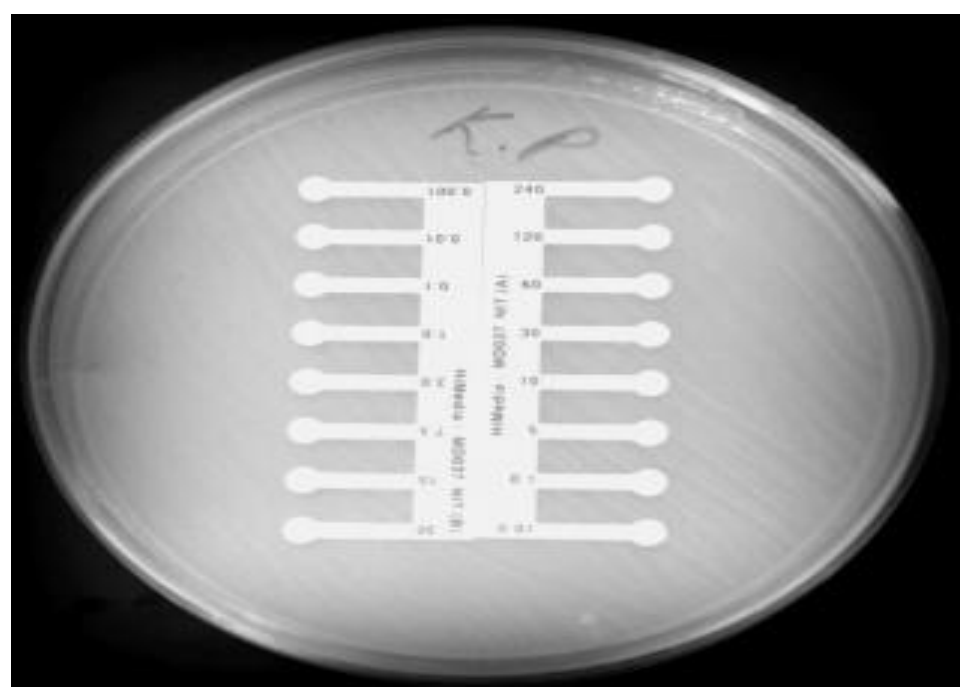

Table.4 Table of Plasmid profilation

\begin{tabular}{|c|c|}
\hline S.No & Name of the strains \\
\hline $\mathbf{1}$ & Klebsiella pneumoniae \\
\hline $\mathbf{2}$ & Klebsiella oxytoca \\
\hline $\mathbf{3}$ & Enterobacter aerogenes \\
\hline $\mathbf{4}$ & Bacillus cirulans \\
\hline $\mathbf{5}$ & Streptococcus equi \\
\hline $\mathbf{6}$ & Acinetobacter johnsoniii \\
\hline $\mathbf{7}$ & Enterococcus phoeniculicola \\
\hline $\mathbf{8}$ & Pseudomonaalcaligenes \\
\hline $\mathbf{9}$ & Serratia antomophila \\
\hline $\mathbf{1 0}$ & Flavobacterium breve \\
\hline
\end{tabular}


Table.5 Result of transformation of resistant gene

\begin{tabular}{|c|c|c|}
\hline \multirow{2}{*}{ Antibiotic } & \multicolumn{2}{|c|}{ Name of the isolate } \\
\hline AMP & + & + \\
\hline EK & + & - \\
\hline AZM & - & - \\
\hline CB & - & + \\
\hline C & + & - \\
\hline CIP & - & + \\
\hline COT & + & - \\
\hline CPM & + & - \\
\hline E & + & + \\
\hline GEN & + & + \\
\hline K & - & - \\
\hline MET & - & - \\
\hline NA & - & + \\
\hline NIT & - & - \\
\hline PB & + & - \\
\hline S & - & - \\
\hline TE & - & + \\
\hline VA & - & - \\
\hline & & \\
\hline
\end{tabular}

Figure.2 Showing plasmid profilation

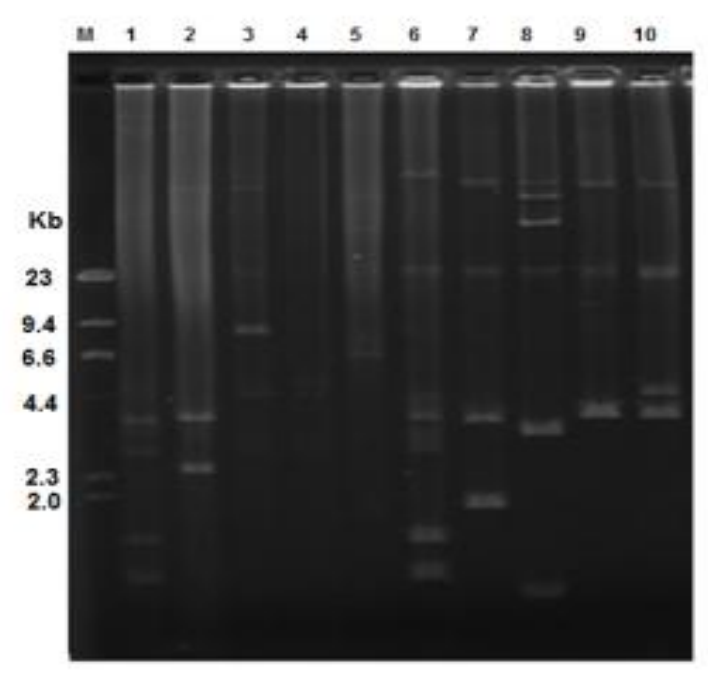

Minimum Inhibitory Concentration (MIC) which they were sensitive, the concentration

Klebsiella pneumoniae and Klebsiella oxytoca showed resistance to almost all the antibiotics tested for MIC and for a few to of antibiotic was very high.ForKlebsiella pneumoniae MIC range for amikacin, ciprofloxacacin, polymyxin B and streptomycin are $256 \mu \mathrm{g}, 240 \mu \mathrm{g}, 120 \mu \mathrm{g}$ and 
$240 \mu \mathrm{g}$, respectively, whereas for K. oxytoca the value for carbenecillin, chloramphenicol and kanamycin are $16 \mu \mathrm{g}, 10 \mu \mathrm{g}$ and $60 \mu \mathrm{g}$, respectively. Kumar et al., (2006) and Siddiqui et al. (1992) reported MIC $>256 \mu \mathrm{g} / \mathrm{ml}$ and $>500 \mu \mathrm{g} / \mathrm{ml}$ for ampicillin in Enterobacteriaceae isolates.

Nadia (2008) showed that the MIC range of tetracycline, ciprofloxacin and azithromycin for Staphylococcus aureus were $0.12 \mathrm{mg} / \mathrm{ml}$ to $32 \mathrm{mg} / \mathrm{ml}$. In the present study the MIC concentration for Klebsiella pneumoniae for amikacin, ciprofloxacin, polymyxin B and Streptomycin was found to be in the range < $240 \mu \mathrm{g}$ which is much higher than the value recommended by Clinical and Laboratory Standards Institute (CLSI) standard (CLSI, 2009). Other strains like Klebsiella oxytoca, Acinetobacter johnsonii, Streptococcus spp, Serratia antomophila and Pseudomonas alcaligenesalso showed resistance upto 4, 0.0, $8,9,4$ and $2 \mu \mathrm{g}$ respectively. However, these isolates were not as resistant to different antibiotics as $K$. pneumonia as the concentration of the antibiotics at which these isolates were sensitive was lesser than that for $K$. pneumoniae but still higher than the recommended value.

To our knowledge this is the first report of incidence of multi drug resistant Klebsiella spp isolated from the aquaculture farms. The strain which showed resistance is highly pathogenic to human health. Thus the MIC results suggest that the untreated sewage released with the hospital discharge may be the source for the bacteria to acquire and disseminate the resistance, and therefore pose a serious potential threat to human health.

\section{Mutation frequency}

Mutation frequency gives an idea of the rate at which resistance to a particular antibacterial is likely to develop during therapy. $K$. oxytoca and Enterobacter aerogenes were exposed to vancomycin at 5 , 10, 15 and 20 times their respective MICs. The isolates developed resistance at significant lower frequencies. For Klebsiella oxytoca colonies appeared upto 15 times of MIC whereas for Enterobacter aerogenes they appeared only upto 10 times of MIC. Similar kind of results was observed by Barnes et al (1992) when they exposed Aeromonas salmonicida to 15 to 20 times of the MIC. A previous study conducted by Stamm (1989) did not find any difference in mutation frequency between sarafloxacin and oxolinic acid. Mutation frequency results obtained in the present study can be explained by the 7day incubation period employed, compared to only $48 \mathrm{hr}$ incubation in the study by Stamm (1989), as mutants to vancomycin were rarely seen at 48 hours of observation even in the present study, indicating that with frequent or longer duration of exposure to antibodies is a sufficient cause for bacteria to mutate and acquire resistance.

\section{Plasmid extraction and transformation}

Plasmids are important vehicles for carrying antibiotic resistance genes (Bennett et al., 2008). High organic load and diverse bacterial communities present in the environment present a unique opportunity for the evolution and transfer of antibiotic resistance genes. Plasmids can harbour genes that confer resistance to most clinically significant antibiotic classes such as macrolides, tetracyclines, cephaloporins, fluoroquinolones, aminoglycosides and Blactam (Bennett et al., 2008; Martinez, 2009).

In the present study 10 isolates were used for the extraction of plasmid, out of which seven strains found to harbour one to six plasmids ranging from 4.4 to $23 \mathrm{kbp}$. The isolates which were taken for plasmid extraction are the ones which either pose potential threat to 
human health or are emerging bacterial fish pathogens like K. pneumoniae, Acinetobacter johnsonii etc. The strain Acinetobacter johnsoniii isolated from the lakeshore fish sample was reported to carry highest number of six plasmids while Enterobacter aerogenes and Enterococcus phoeniculicola was found to carry four numbers of plasmids each. Similar results were reported by $\mathrm{Li}$ et al. (1999), Molina and Galetti (2002), Shafiani and Malik (2003) and Wang et al. (2006). This suggests that antibiotic resistance is encoded on high molecular weight multiple plasmids, and can easily spread in the community. However, in the present study it was noticed that the strains like Klebsiella pneumonia, Klebsiella oxytoca, Enterobacter aerogenes and Enterococcusphoeniculicola which were harbouring more numbers of plasmids showed increased resistance to antibiotics. It has been reported that the isolate harbouring the single high molecular weight plasmid are responsible for multidrug resistance in different strains of Aeromonas strain (Roy et al., 2003; Sorum et al., 2003).

The results of transformation experiment of bacterial plasmid showed that antibiotic resistance in bacterial species is transferable to other bacterial genera (E. coli) through plasmids. Similar previous reports on transformation experiments were reported in plasmid of Vibro isolates and from Penaeid shrimp (Liu et al., 1999; Molina and Galetti, 2002). The results of the transformation experiment in the study using selected isolates as the donor and the E. coli $\mathrm{HB} 101$ as the recipient, indicates that the majority of the plasmid associated resistance markers were transferred to the E. coli strain which was confirmed by antibiotic sensitivity test. In the study it was observed that $E$. coli which was initially sensitive to all the 18 different antibiotics showed resistance to more than 10 antibiotics after transformation. This revealed that the plasmid carry the resistant gene which can be transferred from one to other spp.
In conclusion, the present study indicates how the resistance get acquire and transform from the terrestrial to the aquatic organism. Stillthere is a long-standing debate over the exact role that antimicrobials play in the current antibiotic resistance crisis.

It is in everyone's best interest to slow down the development of antimicrobial resistance, but not a s single group can do it all alone. Although the precise combination of actions required to arrest the current global increase in resistance is unknown, essential elements must include as follows:

1) elimination of unnecessary use, overuse, and abuse of antimicrobial agents in all sectors; 2) universal adherence to principles of judicious use; 3 ) collection and analysis of data on antimicrobial use; 4) surveillance of antimicrobial resistance in all potential reservoirs; 5) mechanisms for identification of and rapid response to dangerous resistance trends; 6) application of infection control strategies, including hygiene and immunization, in human and animal settings; and 7) promoting aggressive research and development of new antimicrobial agents.

\section{Acknowledgement}

The authors would like to highly acknowledge the support rendered by Centre of Aquatic Animal Health Management, School of Aquaculture and Biotechnology, Kerala University of Fisheries and Ocean Studies for smooth running of the research work.

\section{References}

Barnes, D. E., A. E. Tomkinson and A.R. Lehmann (1992). "Mutations in the DNA ligase I gene of an individual with immunodeficiencies and cellular 
hypersensitivity to DNA-damaging agents." Cell 69(3): 495-503.

Bauer, A.W., Kirby, W.M.M., Serris, J.C. and Turck, M. (1966). Antibiotic susceptibility testing by a standardized single disc method. American Journal of Clinical Pathology 45: 493-496.

Bennett, J. W., C. K. Murray, RL Homes and James H. Jorgensen. (2008). "Diminished vancomycin and daptomycin susceptibility during prolonged bacteremia with methicillin-resistant Staphylococcus aureus." Diagnostic microbiology and infectious disease 60(4): 437-440.

Elkin, C. J., P. M. Richardson, H. M. Fourcade, N. M. Hammon, M. J. Pollard, P. F. Predki, T. Glavina, and T. L. Hawkins. 2001. High-throughput plasmid purification for capillary sequencing. Genome research 11:1269-1274.

Farrar WE Jr, Eidson M, Guerry P, Falkow S, Drusin LM, Roberts RB. Interbacterial transfer of $\mathrm{R}$ factor in the human intestine: in-vivo acquisition of $\mathrm{R}$ factor-mediated kanamycin resistance by a multiresistant strain of Shigella sonnei. J Infect Dis. 1972; 126:27-33.

Ines Chen and David Dubnau (2004), "Dna uptake during bacterial transformation". Nature Reviews Microbiology 2, 241-249.

Kumar, M S., V. Lakshmi and R. Rajagopalan (2006). "Occurrence of extended spectrum beta-lactamases among Enterobacteriaceae spp. isolated at a tertiary care institute." Indian Journal of medical microbiology 24(3): 208.

Levy SB. The challenge of antibiotic resistance. Sci Am. Available at: www.sciam.com/1998/0398issue/0398 levy.html\#link6. Accessed April 16, 2001

Li, L., H. Yuan, C. D. weaver, J. Mao, G.H. Farr III, D.J. Sussman, J.Jonkers, D. kimelman and D. Wu. (1999). "Axin and Frat1 interact with dvl and GSK, bridging Dvl to GSK in Wnt- mediated regulation of LEF- 1." The EMBO Journal 18(15): 42334240.

M Lee, D. Hesek, B. Blazque, E. Lastochkin, b Boggesss, Jed F. Fisher and Shahriar Mobashery. (2014). " Catalytic spectrum of the penicillin-binding protein 4 of Pseudomonas aeruginosa, a nexus for the induction of $\beta$ lactam antibiotic resistance" Journal of the American Chemical Society 137 (1): 190-200.

Macrina, F. L., J. A. Tobian, KR Jones, RP Evans (1982). "A cloning vector able to replicate in Escherichia coli and Streptococcus sanguis." Gene 19(3): 345-353.

Martinez, J. L., A. Fajardo, L Garmendia, A Hernandez, J F Linares, L MartinezSolana and M.B. Sanchez. (2009). "A global view of antibiotic resistance." FEMS Microbiology Reviews 33(1): 44-65.

Meyer M, Kolpin DW, Bumgarner JE, Varns JL, Daughtridge JV. Occurrence of antibiotics in surface and groundwater near confined animal feeding operations and wastewater treatment plants using radioimmunoassay and liquid chromatography/electrospray mass spectrometry. Paper presented at 219th meeting of the American Chemical Society; March 26-30, 2000; San Francisco, CA (abstr 1:106)

Molina, W. F. and P. M. Galetti-Jr (2002). "Robertsonian rearrangements in the reef fish Chromis (Perciformes, Pomacentridae) involving chromosomes bearing 5S rRNA genes." Genetics and Molecular Biology 25(4): 373-377.

Nadia Liassine, Patricia Zulueta-Rodriguez, Celine Corbel, Christine Lascols, 
Claude- James Soussy, Emmanuelle Cambau (2008). "First detection of plasmid quinolone resistance in the community setting and in hospitalized patients in Switzerland". Journal of Antimicrobial chemotherapy, 62 (5):1151-1152.

National Research Council, Committee on Drug Use in Food Animals, Panel on Animal Health, Food Safety, and Public Health, Board on Agriculture, National Research Council, Food and Nutrition Board, Institute of Medicine. The Use of Drugs in Food Animals: Benefits and Risks. Washington, DC: National Academy Press; 1999

Roy, I., S. Mitra, (2003). "Calcium phosphate nanoparticles as novel non-viral vectors for targeted gene delivery." International Journal of Pharmaceutics, 250(1): 25-33.

Shafiani, S. and A. Malik (2003). "Tolerance of pesticides and antibiotic resistance in bacteria isolated from wastewaterirrigated soil." World Journal of Microbiology and Biotechnology, 19(9): 897-901.

Shoemaker NB, Want GR, Salyers AA. Evidence for natural transfer of a tetracycline resistance gene between bacteria from the human colon and bacteria from the bovine rumen. Appl Environ Microbiol. 1992; 58: 13131320

Siddiqui, M. N., I. Ahmed, Bader J. Farooqi and Mustaq Ahmed. (1992). "Myonecrosis due to Aeromonas hydrophila following insertion of an intravenous cannula: case report and review." Clinical Infectious Diseases, 14(2): 619-620.

Sørum, H., M. Trine, (2003). "Integroncontaining IncU $\mathrm{R}$ plasmids pRAS1 and pAr-32 from the fish pathogen Aeromonas salmonicida." Antimicrobial agents and chemotherapy 47(4): 1285-1290.

Stamm, J. M. (1989). "In vitro resistance by fish pathogens to aquacultural antibacterials, including the quinolones difloxacin (A-56619) and sarafloxacin (A-56620)." Journal of Aquatic Animal Health 1(2): 135-141.

Swartz MN. Committee on Human Risk Assessment of Using Subtherapeutic Antibiotics in Animal

Wang, J., S. M. Soisson, K. Young, W. Shoop and S. Kodali et al., (2006). "Platensimycin is a selective FabF inhibitor with potent antibiotic properties." Nature 441(7091): 358361.

\section{How to cite this article:}

Hemanta Pokhrel, Salini Gopi, Devika Pillai, C.G. Rakesh and Sneha, K.G. 2018. Determination of Minimum Inhibitory Concentration (MIC), Mutation Frequency and Plasmid extraction and Transformation of Antibiotic Resistant Bacterial Isolate from Aquatic Environment. Int.J.Curr.Microbiol.App.Sci. 7(07): 890-901. doi: https://doi.org/10.20546/ijcmas.2018.707.108 